\title{
EXPOSURE TO MERCURY VAPORS IN DENTAL WORKERS IN POLAND
}

\section{MALGORZATA TRZCINKA-OCHOCKA, ARTUR GAZEWSKI, and RENATA BRODZKA}

Department of Chemical Hazards

Nofer Institute of Occupational Medicine

Łódź, Poland

\begin{abstract}
Objectives: The study aimed at assessing the effect of low-level exposure to mercury (Hg) vapor from amalgam fillings among dental surgery staff in the city of Łódź, Poland. Materials and Methods: The study group was composed of 51 workers (mean age, 39.25 \pm 11.05 years) employed in dental surgeries; the control group comprised 16 white-collar workers (mean age, $40.05 \pm 10.57$ years) of the Nofer Institute of Occupational Medicine, Łódź, who had no or a few amalgam dental fillings. Total urine mercury ( $\mathrm{Hg}-\mathrm{U})$ concentration was determined with cold vapor atomic absorption spectrometry (CV-AAS) based on tin (II) chloride mercury reduction after overnight digestion of urine sample with potassium permanganate in sulfuric acid solution. The reliability of mercury determinations was verified by measuring $\mathrm{Hg}$ concentration in the reference material and via participation in the external quality assessment scheme. Results: No statistically significant differences were found in geometric mean of urine $\mathrm{Hg}$ concentrations between the study and control groups $(\mathrm{GM} \pm \mathrm{SD}, 0.44 \pm 0.440$ and $0.5 \pm 0.270 \mu \mathrm{g} / \mathrm{g}$ creatinine, respectively, $\mathrm{p}=0.242$ ). Among different factors affecting $\mathrm{Hg}$ exposure in dental surgeries, only the duration of dental practice showed a statistically significant influence on total $\mathrm{Hg}-\mathrm{U}(\mathrm{r}=0.3000 ; \mathrm{p}=0.024)$. Having divided the subjects into two groups, with and without amalgam fillings, we noted a statistically significant difference in urine $\mathrm{Hg}$ concentrations $(0.60 \pm 0.720, n=38 ; 0.36 \pm 0.650, n=29 ; p=0.004)$ between these two groups. Conclusions: The results of biological monitoring of dental surgery staff did not reveal current exposure to $\mathrm{Hg}$ vapors from amalgam fillings. However, these dental workers may have been the subject to such an exposure in the past. The only statistically significant correlation was that between total $\mathrm{Hg}-\mathrm{U}$ concentrations and the duration of dental practice.
\end{abstract}

Key words:

Dentists, Mercury, Urine, CV-AAS, $\mathrm{SnCl}_{2}$ reduction

\section{INTRODUCTION}

Exposure to mercury $(\mathrm{Hg})$ or mercury vapor is recognized as a potential health hazard to the staff of dental surgeries. Exposure can occur through a direct skin contact with $\mathrm{Hg}$ or $\mathrm{Hg}$-containing compounds or through inhalation of $\mathrm{Hg}$ vapors. The primary route of exposure is through the respiratory tract: about $80 \%$ of inhaled $\mathrm{Hg}$ is absorbed in the lung [1,2]. Dentists and dental nurses who handle preparation and fitting of $\mathrm{Hg}$-containing amalgam fillings are at risk of being exposed to inorganic mercury, although the recent changes in dental practice that have resulted in a largely decreased use of $\mathrm{Hg}$ amalgams have diminished the health risk among dental surgery workers. Elemental
$\mathrm{Hg}$ is still an important material used in dentistry in Poland. Generally, amalgam fillings have been used since 1895 to fill dental defects. An amalgam filling is a mixture of metallic mercury about $50 \%$, silver $35 \%$, tin $9 \%$, copper $6 \%$, and trace amounts of zinc [3]. Sources of $\mathrm{Hg}$ contamination in dental surgery included expression of excess mercury from amalgam; leakage from amalgam capsules and dispensers; improper storage of scrap amalgam; mercury vaporization from contaminated instruments placed in sterilizers; and mercury vapor generated during the removal of amalgam fillings [3-5]. The implementation of proper mercury hygiene procedures could reduce the potential hazard resulting from $\mathrm{Hg}$ exposure in dental practice $[4,6]$.

Received: January 16, 2007. Accepted: March 23, 2007.

Address reprint requests to Małgorzata Trzcinka-Ochocka PhD, Department of Chemical Hazards, Nofer Institute of Occupational Medicine, św. Teresy 8, 91-348 Łódź, Poland (e-mail: ochocka@imp.lodz.pl). 
To assess low-level occupational mercury exposure of dental staff, urine mercury (Hg-U) concentration was used as an exposure index [4,6-16]. The recent literature data confirm that Hg-U remains the most practical and sensitive marker of monitoring low-level occupational exposure to inorganic mercury [7]. In view of well established dose-effect and dose-response relationships between $\mathrm{Hg}-\mathrm{U}$ concentrations and critical health effects, the recommended $\mathrm{Hg}-\mathrm{U}$ levels are used as the main guideline for workers' health protection. For the assessment of occupational mercury exposure, based on mercury level in urine, the biological exposure indices (BEI) are available. In Poland, the current BEI value for exposure to inorganic or metallic mercury is $35 \mu \mathrm{g} / \mathrm{g}$ creatinine [17]. In Germany, the biological tolerance value (BAT), according to the Commission for the Investigation of Health Hazards of Chemical Compounds in the Work Area for urine, is $100 \mu \mathrm{g} / \mathrm{l}$ [18] while the value of $35 \mu \mathrm{g} / \mathrm{g}$ creatinine for BEI was adopted by the American Conference of Governmental Industrial Hygienists (ACGIH) in 2004 [19].

The recommended value for non-occupational population is $1-5 \mu \mathrm{g} / \mathrm{g}$ creatinine and is considered to be within a normal range [20-22]. Following the regulations of the German Commission on Human Biological Monitoring for Environmental Pollutants, Hg-U concentration, below which there is no risk of adverse health effects, should be $5 \mu \mathrm{g} / \mathrm{g}$ creatinine (HBM I for children and adults), and $20 \mu \mathrm{g} / \mathrm{g}$ creatinine (HBM II) is the concentration, above which there is an increased risk for adverse health effects in susceptible individuals in the general population [18-20]. According to the 1998 German Environmental Survey, the reference $\mathrm{Hg}-\mathrm{U}$ value for adults, aged 18-69 years, without amalgam fillings has recently been revised and lowered from 1.4 to $1.0 \mu \mathrm{g} / 1$ [21].

The purpose of the present study was to determine the current level of occupational mercury exposure among the staff of selected dental surgeries in the city of Łódź, Poland. In our country, the use of amalgam fillings is quite often since they are available free-of-charge for the treatment of molar and pre-molar teeth under the services covered by the National Health Fund. The assessment of exposure to $\mathrm{Hg}$ vapors was based on the determination of total $\mathrm{Hg}-\mathrm{U}$ concentrations in the study population.

\section{MATERIALS AND METHODS}

\section{Study population}

The study group included 51 dentists and dental nurses (aged 25-63 years, mean, 39.25 \pm 11.05 ) working in dental surgeries and whose services are covered by the Regional Division (City of Łódź) of the National Health Fund. The mean duration of dental practice was $14.3 \pm 11.5$ years). The control group comprised 16 healthy individuals (aged 25-56 years; mean, 40.05 \pm 10.57 ), workers of the Nofer Institute of Occupational Medicine, Łódź, who were not occupationally exposed to $\mathrm{Hg}$ vapors.

\section{Questionnaire data}

All the subjects were asked to fill out a questionnaire, which sought information concerning the subject's age, gender, number of seafood servings consumed per week, and number of amalgam fillings in their teeth.

Dentists and their assistants were also asked about their professional career: years of dental practice, number of amalgam fillings placed or removed per week.

\section{Urinary mercury analysis}

Spot urine samples were collected into polypropylene sampling vials (after they had been washed with acid solution and flushed with deionized water).

For mercury analysis, $20 \mathrm{ml}$ of collected urine was transferred to an acid- and deionized water-washed glass tube and then acidified with $0.1 \mathrm{ml}$ of concentration $\mathrm{H}_{2} \mathrm{SO}_{4}$ to $\mathrm{pH}<1$.

For creatinine measurements, $5 \mathrm{ml}$ of urine sample was placed into a polyethylene tube.

Specimens for total mercury and creatinine analyses were frozen at $-20^{\circ} \mathrm{C}$. Urinary creatinine measurements were performed by Perkin Elmer Lambda Spectrophotometer according to Jaffe's picrate method using an Aqua-Med (Aqua-Med., Lódź, Poland).

\section{Instrumentation}

Urine mercury concentration was measured using a MERCURY RA-3 analyzer, model 3110 PL(TESTCHEM, Polish division of Nippon Instruments Corporation) connected with an SC-3 auto-sampler and RD-3 reagent dispenser. 


\section{Determination of total mercury in urine}

Total Hg-U concentrations were determined with cold vapor atomic absorption spectrometry (CV-AAS) [23]. The method involves the determination of the total mercury content after overnight digestion of the urine sample with potassium permanganate in sulfuric acid solution at room temperature. The excess of oxidants is reduced with the hydroxylamine hydrochloride solution. The ionic mercury $\mathrm{Hg}$ (II) from digested urine is converted into $\mathrm{Hg}^{0}$ by a reduction with tin (II) chloride and then vaporized. The vaporized $\mathrm{Hg}$ content is determined from the absorbance measurement at the absorption $\mathrm{Hg}$ wavelength of $253.7 \mathrm{~nm}$.

\section{Quality control}

The accuracy of the method for total $\mathrm{Hg}-\mathrm{U}$ determination was verified by determining urine mercury concentration in reference materials: Seronorm ${ }^{\mathrm{TM}}$ Trace Elements Urine (SERO AS) and ClinCheck® - Urine Control (Recipe®) as well as via the performing laboratory's participation in the German External Quality Assessment Scheme (G-EQUAS) within External Intercomparison Programme 36/2005 for toxicological analyses of biological materials. Our involvement in G-EQUAS was confirmed by a certificate for urinary mercury determination in the fields of occupational medicine and environmental health.

\section{Statistical analysis}

Student's t-test, simple linear regression analysis, and Pearson correlation coefficients were used for statistical analysis. When geometric means of urinary mercury were calculated for the control group, one person with a particularly high level of urinary mercury was excluded from the analysis.

\section{RESULTS}

\section{Biological monitoring}

Table 1 displays geometric means and $\mathrm{Hg}-\mathrm{U}$ concentration ranges in the study and control groups. The values of total $\mathrm{Hg}-\mathrm{U}(0.44 \pm 0.44$ and $0.57 \pm 0.27 \mu \mathrm{g} / \mathrm{g}$ creatinine, respectively) did not show statistically significant differences between these two groups ( $p=0.242$ ). The numbers of amalgam fillings (arithmetic means) amounted to $1.16 \pm 1.44$ and $1.53 \pm 1.07$, respectively, with no statistically significant differences.

\section{Correlations}

In our study, the influence of different factors, such as years of dental practice, numbers of amalgam fillings placed/removed per week, daily working hours of dental staff, and amalgam restorations in the dental staff and control group, on total urinary mercury excretion was investigated (Table 2).

Among different factors that may have influence on $\mathrm{Hg}$ vapor exposure, listed in Table 2, a statistically significant correlation between $\mathrm{Hg}-\mathrm{U}$ concentration and duration of dental practice $(r=0.3 ; \mathrm{p}<0.05)$ was noted only in the

Table 1. Geometric means and concentration ranges for urinary mercury $(\mathrm{Hg}-\mathrm{U})$ in the exposed and control groups

\begin{tabular}{lcccc}
\hline \multirow{2}{*}{ Group } & No. of & \multicolumn{3}{c}{ Mercury urinary concentrations } \\
\cline { 3 - 5 } & $\begin{array}{c}\text { amalgams } \\
\text { (arithmetic } \\
\text { mean })\end{array}$ & $\begin{array}{c}\text { No. of } \\
\text { subjects }\end{array}$ & $\begin{array}{c}\text { Mean* } \pm \text { SD } \\
(\mu \mathrm{g} / \mathrm{g} \\
\text { creatinine })\end{array}$ & $\begin{array}{c}\text { Range } \\
(\mu \mathrm{g} / \mathrm{g} \\
\text { creatinine })\end{array}$ \\
\hline Exposed & $1.16 \pm 1.40$ & 51 & $0.44 \pm 0.44$ & $0.08 \div 1.95$ \\
Control & $1.53 \pm 1.07$ & 15 & $0.57 \pm 0.27$ & $0.22 \div 1.07$ \\
\hline
\end{tabular}

* Geometric mean and standard deviation.

Table 2. Relationship between questionnaire data and total urine mercury (Hg-U) concentrations (in $\mu \mathrm{g} / \mathrm{g}$ creatinine)

\begin{tabular}{lccccc}
\hline \multicolumn{1}{c}{ Questionnaire item } & Group & Linear regression equation & $\mathrm{r}$ & $\begin{array}{c}\text { No. of } \\
\text { subjects }\end{array}$ & $\mathrm{P}$ \\
\hline No. of years (duration) of dental practice & Exposed & $\mathrm{y}=0.0120 \mathrm{x}+0.4119$ & 0.3000 & 51 & 0.024 \\
No. of amalgams placed/removed per week & Exposed & $\mathrm{y}=0.0073 \mathrm{x}+0.5499$ & 0.0980 & 51 & 0.495 \\
No. of daily working hours of dental staff & Exposed & $\mathrm{y}=0.0039 \mathrm{x}+0.5587$ & 0.0173 & 51 & 0.905 \\
No. of amalgams in the investigated exposed subjects & Exposed & $\mathrm{y}=0.0546 \mathrm{x}+0.5212$ & 0.1780 & 51 & 0.211 \\
No. of amalgams in the investigated control subjects & Control & $\mathrm{y}=0.0660 \mathrm{x}+0.5210$ & 0.2740 & 16 & 0.323 \\
\hline
\end{tabular}

$\mathrm{r}$ - linear correlation coefficient; $\mathrm{P}$ - level of significance. 


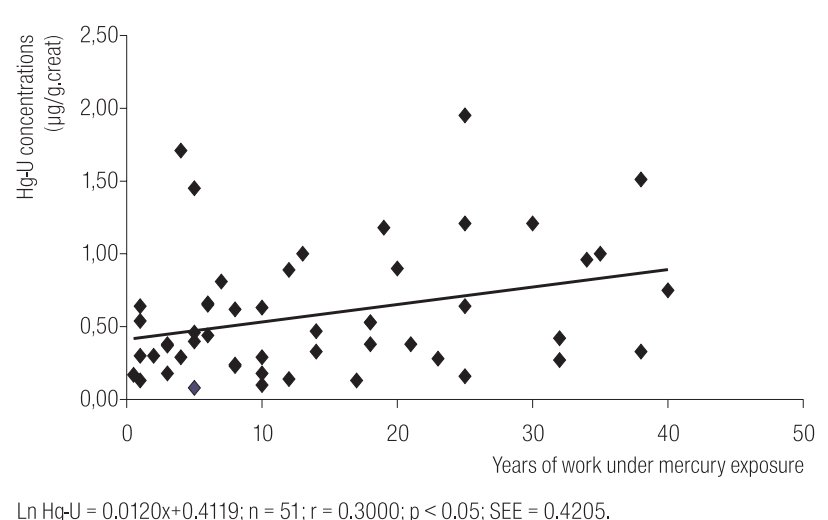

Fig. 1. Relationship between years of work under exposure to mercury and urine mercury $(\mathrm{Hg}-\mathrm{U})$ concentrations.

exposed group (Fig. 1). For other factors likely to affect urinary $\mathrm{Hg}$ excretion, the observed correlations were not statistically significant $(\mathrm{p}>0.05)$ (Table 2$)$.

\section{Exposure to mercury from amalgam restorations}

In our project, we estimated mercury exposure from the total number of amalgam fillings in the oral cavity of the examined subjects. To this end, this population was divided into two groups with (subgroup $1 ; \mathrm{n}=38$ ) and without (subgroup 2; $\mathrm{n}=29$,) amalgam fillings. The geometric mean of $\mathrm{Hg}-\mathrm{U}$ concentration in subgroup 1 (No. of amalgam fillings, $2.36 \pm 1.15$ ) was $0.60 \pm 0.720 \mu \mathrm{g} / \mathrm{g}$ creatinine compared to $0.36 \pm 0.650 \mu \mathrm{g} / \mathrm{g}$ creatinine in subgroup 2 (without amalgam fillings). Statistically significant difference in $\mathrm{Hg}-\mathrm{U}$ concentrations was found between the two subgroups. Hg-U concentrations in the subjects of subgroup 1 were significantly higher than those in subgroup 2 (Table 3).

\section{DISCUSSION}

A number of reports have shown that exposure to mercury vapor in dental practice can reach relatively high levels (Table 4). Joselow et al. [8], who in 1968 summarized the results of studies on $\mathrm{Hg}$ exposure in the U.S. dental profession ( $\mathrm{n}=50)$, reported that average $\mathrm{Hg}$ concentration ranged from $40.0 \mu \mathrm{g} / \mathrm{l}$ up to $155 \mu \mathrm{g} / \mathrm{l}$ (Table 4). At that time, very high levels of $\mathrm{Hg}$ exposure could be explained by low hygiene of work with mercury. Many dentists kneaded the amalgam mass in the palm of their hands. New dental technologies and better hygiene standards have significantly reduced the exposure. In 1985, Naleway et al. [9] published the results obtained under the health-screening program for 4272 U.S. dentists, including an analysis of $\mathrm{Hg}-\mathrm{U}$. At that time, the mean urine mercury concentrations were much lower $(14.2 \mu \mathrm{g} / \mathrm{l} ; \mathrm{SD}=25.4)$ than those reported by Joselow et al. [8] and were positively related to weekly hours of practice, number of amalgams placed or removed, method of amalgam fillings preparation and application, type of amalgam capsules used, and type of cooling and heating systems. The U.S. data indicated a dramatic decline in $\mathrm{Hg}-\mathrm{U}$ concentrations, from $40 \mu \mathrm{g} / \mathrm{l}$ in 1968, through $11.9 \mu \mathrm{g} / \mathrm{l}$ in 1987, to $4.9 \mu \mathrm{g} / \mathrm{l}$ in 1995 (Table 4). The factors accounting for this decrease might be a better work hygiene when handling amalgam fillings, decreasing caries prevalence since 1995, and also to some extent due to the use of alternative materials for dental fillings. In Sweden, the exposure to $\mathrm{Hg}$ vapor in the dental profession was much lower in 1986 and in 1997 comparable to the American data. The mean values for $\mathrm{Hg}-\mathrm{U}$ in the dental

Table 3. Mean urine mercury ( $\mathrm{Hg}-\mathrm{U})$ concentrations in subgroup 1 with and subgroup 2 without amalgam fillings

\begin{tabular}{|c|c|c|c|c|}
\hline \multirow{2}{*}{ Subgroup } & \multirow{2}{*}{$\begin{array}{l}\text { No. of amalgam fillings } \\
\text { (arithmetic mean) }\end{array}$} & \multicolumn{3}{|c|}{ Mercury urinary concentration } \\
\hline & & No. of subjects & $\begin{array}{c}\text { Mean } * \pm S D \\
(\mu \mathrm{g} / \mathrm{g} \text { creatinine })\end{array}$ & $\begin{array}{c}\text { Range } \\
(\mu \mathrm{g} / \mathrm{g} \text { creatinine })\end{array}$ \\
\hline $\begin{array}{l}\text { With amalgam fillings } \\
\text { (subgroup 1) }\end{array}$ & $2.36 \pm 1.15$ & 38 & $0.60^{\mathrm{a}} \pm 0.720$ & $0.13 \div 1.95$ \\
\hline $\begin{array}{l}\text { Without amalgam fillings } \\
\text { (subgroup 2) }\end{array}$ & 0 & 29 & $0.36 \pm 0.650$ & $0.10 \div 1.51$ \\
\hline
\end{tabular}

* Geometric mean and standard deviation.

${ }^{\text {a }} \mathrm{P}$ (level of significance) $=0.004$ for Hg-U in subgroup 1 vs. subgroup 2. 
Table 4. Mercury concentration in urine samples obtained from the dental staff: the results of major studies

\begin{tabular}{|c|c|c|c|c|}
\hline Country & Year & Mean & Range & References \\
\hline USA & 1968 & $40 \mu \mathrm{g} / \mathrm{l}(\mathrm{n}=50)$ & $0 \div 155 \mu \mathrm{g} / \mathrm{l}$ & Joselow MM et al. [8] \\
\hline USA & 1985 & $14.2 \mu \mathrm{g} / \mathrm{l}(\mathrm{SD}=25.4)(\mathrm{n}=4272)$ & $5 \%>50 \mu \mathrm{g} / 1$ & Naleway C et al. [9] \\
\hline Sweden & 1986 & $4.2 \mu \mathrm{g} / \mathrm{l}(\mathrm{n}=505)$ & $<1 \div 70.6 \mu \mathrm{g} / \mathrm{l}$ & Nilsson B et al. [10] \\
\hline Control group & & $2.7 \mu \mathrm{g} / \mathrm{l}(\mathrm{n}=41)$ & & \\
\hline USA & 1987 & $11.9 \mu \mathrm{g} / \mathrm{l}(\mathrm{n}=1298)$ & $0 \div 396 \mu \mathrm{g} / \mathrm{l}$ & Langan DC et al. [6] \\
\hline The Netherlands & 1988 & $11.4 \mu \mathrm{g} / \mathrm{l}(\mathrm{n}=312)$ & $5.1 \div 22.3 \mu \mathrm{g} / 1$ & Herber RFM et al. [11] \\
\hline Norway & 1990 & $8.2 \mu \mathrm{g} / \mathrm{l}(\mathrm{n}=945)$ & $0 \div 55 \mu \mathrm{g} / 1$ & Jokstad A [12] \\
\hline USA & 1995 & $4.9(\mathrm{SD}=6.61) \mu \mathrm{g} / \mathrm{l}(\mathrm{n}=1352)$ & $2 \%>20 \mu \mathrm{g} / \mathrm{l}$ & Martin MD et al. [4] \\
\hline Sweden & 1997 & $5.3 \mu \mathrm{g} / \mathrm{g}$ creatinine $(\mathrm{n}=44)$ & $1.6 \div 26.7 \mu \mathrm{g} / \mathrm{g}$ creatinine & Langworth S et al. [13] \\
\hline Control group & & $4.1 \mu \mathrm{g} / \mathrm{g}$ creatinine $(\mathrm{n}=44)$ & $0 \div 23.1 \mu \mathrm{g} / \mathrm{g}$ creatinine & \\
\hline Venezuela & 2000 & $\begin{array}{c}22.3(\mathrm{SD}=6.1) \mu \mathrm{g} / \mathrm{g} \text { creatinine } \\
(\mathrm{n}=66)\end{array}$ & $6.3 \div 34.4 \mu \mathrm{g} / \mathrm{g}$ creatinine & Rojas M et al. [14] \\
\hline Mexico & 2002 & $3.2 \mu \mathrm{g} / \mathrm{l}(\mathrm{SD}=2.74)(\mathrm{n}=30)$ & $0.2 \div 12 \mu \mathrm{g} / \mathrm{l}$ & Millán MAP et al. [15] \\
\hline $\begin{array}{l}\text { United Kingdom } \\
\text { Control group }\end{array}$ & 2002 & $\begin{array}{c}1.45(\mathrm{SD}=1.55) \mu \mathrm{g} / \mathrm{g} \text { creatinine }(\mathrm{n}=162) \\
0.38(\mathrm{SD}=0.38) \mu \mathrm{g} / \mathrm{g} \text { creatinine } \\
(\mathrm{n}=163)\end{array}$ & $0.01 \div 11.74 \mu \mathrm{g} / \mathrm{g}$ creatinine & Ritchie KA et al. [16] \\
\hline
\end{tabular}

staff were $4.2 \mu \mathrm{g} / \mathrm{l}(\mathrm{n}=505)$ and $5.3 \mu \mathrm{g} / \mathrm{g}$ creatinine $(\mathrm{n}=$ 44) $[10,13]$.

In some countries, the mean and range of $\mathrm{Hg}-\mathrm{U}$ concentrations in the dental staff are still rather high. In Venezuela, the mean urine mercury level amounted to $22.3 \mu \mathrm{g} / \mathrm{g}$ creatinine in 2000 [14]. The high concentration in some dentists may indicate that a substantial change in work hygiene would be necessary.

Biological monitoring of selected dental surgeries in the city of Łódź, Poland, indicates the absence of current exposure to $\mathrm{Hg}$ vapors from placed/removed amalgam fillings. The HG-U results within the range of $0.08-1.95 \mu \mathrm{g} / \mathrm{g}$ creatinine (study group) and 0.22-1.07 $\mu \mathrm{g} / \mathrm{g}$ creatinine (control group) (Table 1) are substantially below the current biological threshold limit of $35 \mu \mathrm{g} / \mathrm{g}$ creatinine for occupationally exposed workers [17] and are within the range of reference values, $1.0-5.0 \mu \mathrm{g} / \mathrm{g}$ creatinine for $\mathrm{Hg}-\mathrm{U}$ in non-exposed adults (18-69-years-old) with no amalgam fillings [20,21]. No statistical differences in the mean total $\mathrm{Hg}$-U between the dental staff and the control group may point to a much lower exposure to $\mathrm{Hg}$ vapors than that reported earlier. A lower or no exposure in this group of practitioners may result from more modern standards of dental practice. 
Statistically significant correlation was found between urinary mercury concentration and years of dental practice $(\mathrm{p}<0.05)$ (Fig. 1, Table 2). The majority of the dental practitioners had been exposed to mercury for many years (mean, 14.3 years) and their exposure to inorganic mercury in the past was probably higher than in the present study.

In the study group, statistically significant differences ( $p=0.004$ ) were found in $\mathrm{Hg}-\mathrm{U}$ concentration between the subjects with (subgroup I) and without (subgroup II) amalgam fillings (Table 3). The release of mercury vapor from amalgams is well documented [5,24-26]. It is estimated that a single $0.4 \mathrm{~cm}$ amalgam filling releases daily about $15 \mu \mathrm{g}$ mercury. In a patient with 6 amalgam dental fillings, the volume of mercury released daily amounts to about $60 \mu \mathrm{g}$ [3,5]. On the other hand, mercury is also absorbed with food and environmental media, such as air and water. A daily mercury intake with seafood is estimated at about $2.3 \mu \mathrm{g}$ while with other foodstuffs, air, and water at about $0.3 \mu \mathrm{g}$.

In many countries, including Poland, the use of amalgam as a filling material has substantially declined over the last decade. In the countries for which relevant statistical data are available, such as the USA, the UK, Australia, and Scandinavian countries, the use of amalgam was found to decrease by several times [25]. There is a number of restrictions on its use worldwide. For example, in Germany, amalgam fillings should not be placed or removed in pregnant women.

The high level of mercury exposure in the past might be connected with the method of preparing amalgam fillings. Amalgam was rubbed by hand and then mixed mechanically. These procedures might have contributed to an increased concentration of mercury vapors in the ambient air of dental surgeries as evidenced by high $\mathrm{Hg}$ - $\mathrm{U}$ levels detected earlier in dentists. The level of exposure depended on the type of dental equipment, internal ventilation system, floor covering, and mercury residues on the floor as well as on the preparation, insertion and removal of amalgam fillings. The use of disposable amalgam capsules and adhesive tape to check whether the capsules are airtight when reused, have contributed to a $20-50 \%$ decrease in mercury vapor concentration in the ambient air. New dental technologies and the introduction of more restrictive rules of occupational hygiene have brought about a radical reduction of mercury exposure in dental surgeries [6,25-26].

Poland has no regulations prohibiting or restricting the placement of dental amalgam fillings, however, due to the widespread use of composite resins, amalgams are now less often used compared to the past.

\section{CONCLUSIONS}

The results of the study indicate that current exposure to mercury vapors in the dental profession in Poland is very low. In some dental surgeries covered by the study, no evidence of exposure to mercury vapors was found, nor were there any statistically significant differences between the study group and controls. In the study group, among factors likely to contribute to $\mathrm{Hg}$ exposure in dentists, a statistically significant correlation was noted only between years of work in dental surgery and total urine mercury concentrations. This could imply previous exposure to mercury vapors in this group.

Biological monitoring based on urinary mercury determination is a valuable tool in assessing mercury exposure and the effectiveness of hygiene practice in the dental surgery staff.

\section{Acknowledgements:}

The authors thank Dr. Robert Budziński, Director, Łódź-Polesie Division of the Health Care Department, Dr. Bożena Bogucka, Head, Dental Center at the Health Care Department, Prof. Danuta Piątowska, Head, Department of Conservative Dentistry, Medical University Hospital No. 6, SP ZOZ, and Dr. Tomasz Kercz, Director, TMK Specialistic Dental Centre, NZOZ, for their kind consent to conduct the present project in their medical settings. We would also like to thank our colleagues, Wojciech Sobala, MSc, for performing statistical analysis, Elżbieta Hiler and Małgorzata Gontarek for their technical assistance in creatinine determinations. 


\section{REFERENCES}

1. IPCS. Environmental Health Criteria 118. Inorganic Mercury. WHO. Geneva 1991.

2. Bjorkman L, Sandborgh-Englund G, Ekstrand J. Mercury in saliva and feces after removal of amalgam fillings. Toxicol Appl Pharmocol 1997;144:156-62.

3. Mason HJ, Hindell P. Williams NR. Biological monitoring and exposure to mercury. Occup Med 2001;1:2-11.

4. Martin MD, Naleway C, Chou HN. Factors contributing to mercury exposure in dentists. J Am Dental Assoc 1995;126:1502-11.

5. Lorscheider F, Vimy M, Summers AO. Mercury exposure from "silver" tooth fillings: emerging evidence questions a traditional dental paradigm. FASEB J 1995;9:504-8.

6. Langan DC, Steffek AJ, Naleway CA. Mercury hygiene practices. Calif Dental Assoc 1987;14:24-9.

7. Morton J, Mason HJ, Ritchie KA, White M. Comparison of hair, nails and urine for biological monitoring of low level inorganic mercury exposure in dental workers. Biomarkers 2004;9:47-55.

8. Joselow MM, Goldwater IJ, Alvarez A, Hemdon J. Absorption and excretion of mercury in man. XV. Occupational exposure among dentists. Arch Environ Health 1968;17:39-43.

9. Naleway C, Sakakguchi R, Michell E, Muller T, Ayer WA, Hefferren JJ. Urinary mercury levels in US dentists, 19751983: review of Health Assessment Program. J Amer Dental Assoc 1985;111:37-42.

10. Nilsson B, Nilsson B. Mercury in dental practice. II. Urinary mercury excretion in dental personnel. Swed Dent J 1986;10:221-32.

11. Herber RFM, de Gee AJ, Wibowo AAE. Exposure of dentists and assistants to mercury: mercury levels in urine and hair related to conditions of practice. Comm Dent Oral Epidem 1988;16:153-8.

12. Jokstad A. Mercury excretion and occupational exposure of dental personnel. Comm Dent Oral Epidem 1990;18:143-8.

13. Langworth S, Sällsten G, Barregård L, Cynkier I, Lind ML, Söderman E. Exposure to mercury vapor and impact on health in the dental profession in Sweden. J Dent Res 1997;76:1397-404 .

14. Rojas M, Guevara H, Rincón R, Rodriques M, Olivet C. Occupational exposure and health effects on metallic mercury among dentists and dental assistants; a preliminary study. Valencia, Venezuela: 1998. Acta Cientifica Venezolana 2000;51:32-8.

15. Millan MAP, Correa FG. Determination of mercury in urine of Mexican dentists by neutron activation analysis. J Radioanal Nucl Chem 2002;2:305-9.

16. Ritchie KA, Gilmour WH, Macdonald EB, Burke FJT, McGowan DA, Dale IM, et al. Health and neuropsychological functioning of dentists exposed to mercury. Occup Environ Med 2002;59:287-93.

17. CIOP/PIP, 2003. Intersectoral Committee for MAC/MAI Values in Work Environment. Central Institute of Labour Protection, Warsaw, Poland 2003, p. 119 [in Polish].

18. DFG. List of MAK and BAT Values 2004, Maximum Concentrations and Biological Tolerance Values at the Workplace, Commission for the Investigation of Health Hazards of Chemical Compounds in the Work Area, Deutsche Forschungsgemeinschaft, report No. 40, Wiley-Vch, 2004.

19. ACGiH. TLVs and BEIs, threshold limit values for chemical substances and physical agents and biological exposure indices, 2004.

20. Ewers U, Krause C, Schulz C, Wilhelm M. Reference values and human biological monitoring values for environmental toxins. Int Arch Occup Environ Health 1999;72:255-60.

21. Wihelm M, Ewers U, Schulz C. Revised and new reference values for some trace elements in blood and urine for human biomonitoring in environmental medicine. Int J Hyg Environ Health 2004;207:69-73.

22. Jakubowski M, Trzcinka-Ochocka M. Biological monitoring of exposure: Trends and key developments. J Occup Health 2005;47:22-48.

23. Gazewski A, Trzcinka-Ochocka M, Brodzka R. Determination of total mercury in urine by $C V A A S$. Acta Toxicol. In press.

24. Factor-Litvak P, Hasselgren G, Jacobs D, Begg M, Kline J, Geier J, et al. Mercury derived from dental amalgams and neuropsychologic function. Environ Med 2003;11(5):719-23.

25. Burke FJT. Amalgam to tooth-coloured materials-implications for clinical practice and dental education; governmental restrictions and amalgam-usage survey results. J Dent 2004; $32: 343-50$.

26. Owecka M: Amalgam fillings in dental practice - controversies and questions.PublicHealth2002;112(1):126-9 [inPolish]. 